\title{
Generalized Zagreb index of some dendrimer structures
}

\author{
Prosanta Sarkar ${ }^{\mathrm{a}}$, Nilanjan De ${ }^{\mathrm{b}^{*}}$, İsmail Naci Cangül ${ }^{\mathrm{c}}$ and Anita Pal ${ }^{\mathrm{a}}$

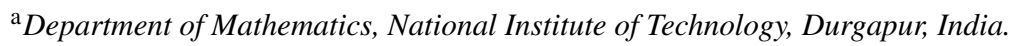 \\ ${ }^{\mathrm{b}}$ Department of Basic Sciences and Humanities (Mathematics), Calcutta Institute of Engineering and Management, Kolkata, India. \\ ${ }^{\mathrm{c}}$ Uludă̆ University, Mathematics, Görükle 16059, Bursa, Turkey. \\ *Corresponding author E-mail: de.nilanjan@ rediffmail.com
}

\section{Article Info}

Keywords: Dendrimers, Generalized Zagreb index, Vertex degree-based topological indices

2010 AMS: 05C35, 05C07, 05C40

Received: 18 May 2018

Accepted: 8 September 2018

Available online: 30 September 2018

\begin{abstract}
Chemical graph theory, is a branch of mathematical chemistry which deals with the nontrivial applications of graph theory to solve molecular problem. A chemical graph is represent a molecule by considering the atoms as the vertices and bonds between them as the edges. A topological index is a graph based molecular descriptor, which is graph theoretic invariant characterising some physicochemical properties of chemical compounds. Dendrimers are generally large, complex, and hyper branched molecules synthesized by repeatable steps with nanometre scale measurements. In this paper, we study the $(a, b)$-Zagreb index of some regular dendrimers and hence obtain some vertex degree based topological indices.
\end{abstract}

\section{Introduction}

A molecule in chemical graph theory generally represented by graph $G=(V(G), E(G))$ where $V(G)$ denote the vertex set and $E(G)$ is the edge set of $G$, the vertices are consider as atoms of the molecule and edges are bonds between them. The degree of a vertex $v \in V(G)$ is the number of those vertices in $G$ such that which are adjacent to $v$ and is denoted as $d_{G}(v)$. A topological index of a graph is the real number obtain from that graph numerically and is same for graph isomorphism. Study of various topological indices for chemical structures of various molecules play an important role in medical and pharmaceutical fields to predicting biological activity of new molecules and drugs. Dendrimers is a type of macromolecules that could be synthesized from monomers by reproducible procedures. Generally dendrimers are large, complex and hyper branch with multiple functional groups on the surface. Dendrimer was first introduced in 1985 by D.A. Tomalia et al. [1]. Now a days more than forty families of dendrimers are present which are carries unique properties. These specific properties make dendrimers suitable for various applications in medical and industrial technology. Dendrimers are used in vitro diagnostic cardiac testing, as contrast agents for magnetic resonance. Magnetic resonance imaging (MRI) is a diagnostic process to producing anatomical images of organs and blood vessels. Recently, U. Ahmad et al. studied the atom-bond connectivity indices of certain families of dendrimers in [2], Y. Bashir et al. studied forgotten topological index of some dendrimers structure in [3]. In this paper, we derived the exact expressions of the generalized Zagreb index or $(a, b)$-Zagreb index of some regular dendrimers and hence as a special case we obtain some important degree based topological indices such as Zagreb indices, forgotten topological index, redefined Zagreb index, general first Zagreb index, general Randić index, symmetric division deg index from using our derived results. Gutman and Trinajestić in a paper, "to study the total $\pi$-electron energy $(\varepsilon)$ of carbon atoms" introduced the Zagreb indices in 1972 [4] and are defined as

$$
M_{1}(G)=\sum_{v \in V(G)} d_{G}(v)^{2}=\sum_{u v \in E(G)}\left[d_{G}(u)+d_{G}(v)\right]
$$

and

$$
M_{2}(G)=\sum_{u v \in E(G)} d_{G}(u) d_{G}(v)
$$

We refer our reader to [5, 6], for some recent study about these indices. The "forgotten topological index" or F-index was introduced by Gutman and Trinajestić [4], in the same paper where Zagreb indices were introduced and is defined as

$$
F(G)=\sum_{v \in V(G)} d_{G}(v)^{3}=\sum_{u v \in E(G)}\left[d_{G}(u)^{2}+d_{G}(v)^{2}\right]
$$


For further study about this index we refer our reader to [7, 8, 9]. The redefined Zagreb index was first introduced in 2013 by Ranjini et al. [10] and is defined as

$$
\operatorname{ReZM}(G)=\sum_{u v \in E(G)} d_{G}(u) d_{G}(v)\left[d_{G}(u)+d_{G}(v)\right] .
$$

For some recent study about this index we refer our reader to [11, 12]. Li and Zheng was introduced the general Zagreb index in [13], and is defined as

$$
M^{\alpha}(G)=\sum_{u \in V(G)} d_{G}(u)^{\alpha}
$$

where, $\alpha \neq 0,1$ and $\alpha \in \mathbb{R}$. Clearly, when $\alpha=2$ we get first Zagreb index and when $\alpha=3$ it gives the F-index. In 2001, Gutman and Lepović generalized the Randić index in [14] and is defined as

$$
R_{a}=\sum_{u v \in E(G)}\left\{d_{G}(u) \cdot d_{G}(v)\right\}^{a}
$$

where, $a \neq 0, a \in \mathbb{R}$. The Symmetric division deg index of a graph is defined as

$$
S D D(G)=\sum_{u v \in E(G)}\left[\frac{d_{G}(u)}{d_{G}(v)}+\frac{d_{G}(v)}{d_{G}(u)}\right] .
$$

For further study about this index, we refer our reader to [15, 16, 17]. Based on some well known vertex degree based topological indices Azari et al. [18], in 2011 introduced a generalized version of vertex degree based topological index, named as generalized Zagreb index or the $(a, b)$-Zagreb index and is defined as

$$
Z_{a, b}(G)=\sum_{u v \in E(G)}\left(d_{G}(u)^{a} d_{G}(v)^{b}+d_{G}(u)^{b} d_{G}(v)^{a}\right) .
$$

We refer our reader to [19, 20, 21], for further study about this index. It is shown that in table 1 all the topological indices discussed previously in this paper, are derived from this $(a, b)$-Zagreb index for some particular values of $a$ and $b$.

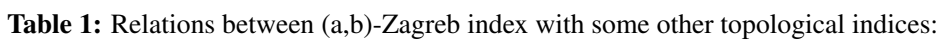

\begin{tabular}{|c|c|}
\hline Topological index & Corresponding $(a, b)$-Zagreb index \\
\hline First Zagreb index $M_{1}(G)$ & $Z_{1,0}(G)$ \\
\hline Second Zagreb index $M_{2}(G)$ & $\frac{1}{2} Z_{1,1}(G)$ \\
\hline Forgotten topological index $F(G)$ & $Z_{2,0}(G)$ \\
\hline Redefined Zagreb index $\operatorname{Re} Z M(G)$ & $Z_{2,1}(G)$ \\
\hline General first Zagreb index $M^{a}(G)$ & $Z_{a-1,0}(G)$ \\
\hline General Randić index $R_{a}$ & $\frac{1}{2} Z_{a, a}$ \\
\hline Symmetric division deg index $S D D(G)$ & $Z_{1,-1}(G)$ \\
\hline
\end{tabular}

\section{Main Results}

In this section, we derived generalized Zagreb index of some dendrimers. First, we consider the regular dendrimer $G[n]$ with exactly $n$ generations. The edge sets of dendrimer $G[n]$ are divided into three parts and are shown as follows:

$$
\begin{aligned}
& E_{1}(G[n])=\left\{e=u v \in E(G[n]): d_{G[n]}(u)=2 \text { and } d_{G[n]}(v)=2\right\} \\
& E_{2}(G[n])=\left\{e=u v \in E(G[n]): d_{G[n]}(u)=2 \text { and } d_{G[n]}(v)=3\right\} \\
& E_{3}(G[n])=\left\{e=u v \in E(G[n]): d_{G[n]}(u)=2 \text { and } d_{G[n]}(v)=1\right\}
\end{aligned}
$$

note that, $\left|E_{1}(G[n])\right|=\left(2^{n+3}-5\right),\left|E_{2}(G[n])\right|=\left(3 \times 2^{n+1}-6\right),\left|E_{3}(G[n])\right|=2^{n+1}$. The two dimensional structure of a regular dendrimer $G[n]$ with 6-levels is shown in figure 1 .

Theorem 2.1. The $(a, b)$-Zagreb index of the regular dendrimer $G[n]$ is given by

$$
Z_{a, b}(G[n])=\left(2^{n+3}-5\right) \cdot 2^{a+b+1}+\left(3 \times 2^{n+1}-6\right)\left(2^{a} \cdot 3^{b}+2^{b} \cdot 3^{a}\right)+2^{n+1}\left(2^{a}+2^{b}\right) .
$$

Proof. Applying the definition of (a,b)-Zagreb index, we get

$$
\begin{aligned}
Z_{a, b}(G[n]) & =\sum_{u v \in E(G[n])}\left(d_{G[n]}(u)^{a} d_{G[n]}(v)^{b}+d_{G[n]}(u)^{b} d_{G[n]}(v)^{a}\right) \\
& =\sum_{u v \in E_{1}(G[n])}\left(2^{a} 2^{b}+2^{b} 2^{a}\right)+\sum_{u v \in E_{2}(G[n])}\left(2^{a} 3^{b}+2^{b} 3^{a}\right)+\sum_{u v \in E_{3}(G[n])}\left(2^{a} 1^{b}+2^{b} 1^{a}\right) \\
& =\left|E_{1}(G[n])\right|\left(2^{a} 2^{b}+2^{b} 2^{a}\right)+\left|E_{2}(G[n])\right|\left(2^{a} 3^{b}+2^{b} 3^{a}\right)+\left|E_{3}(G[n])\right|\left(2^{a} 1^{b}+2^{b} 1^{a}\right) \\
& =\left(2^{n+3}-5\right) \cdot 2^{a+b+1}+\left(3 \times 2^{n+1}-6\right)\left(2^{a} 3^{b}+2^{b} 3^{a}\right)+2^{n+1}\left(2^{a}+2^{b}\right) .
\end{aligned}
$$

Hence, the theorem. 


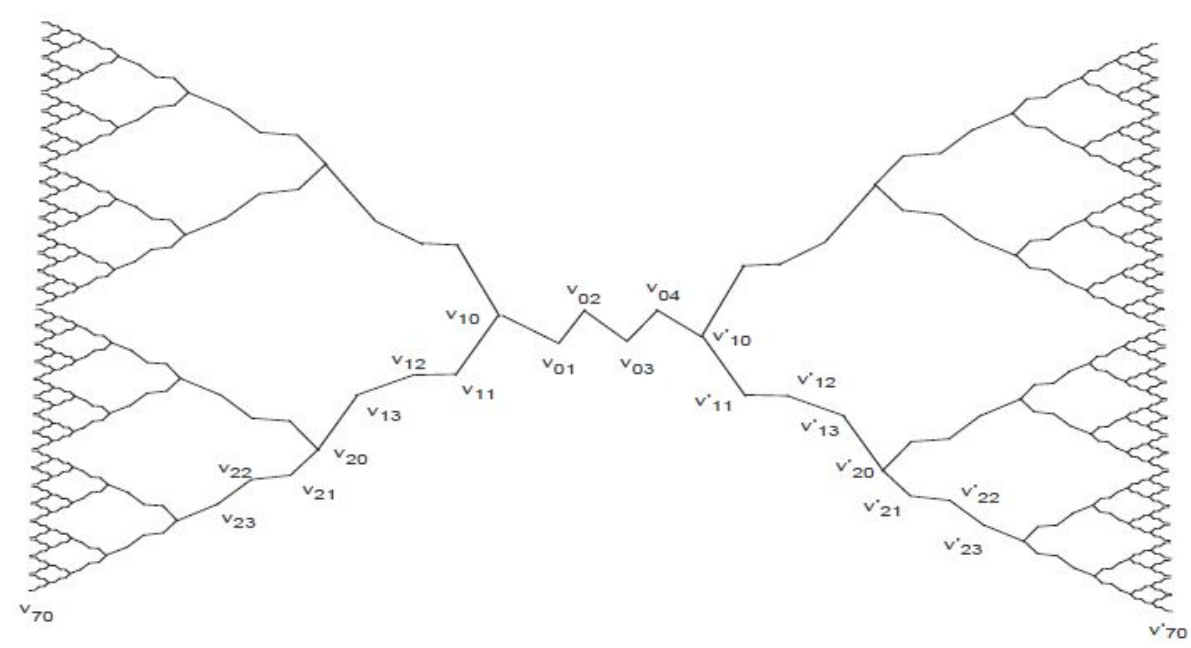

Figure 2.1: The two dimensional structure of regular dendrimer $G[n]$ for $\mathrm{n}=6$.

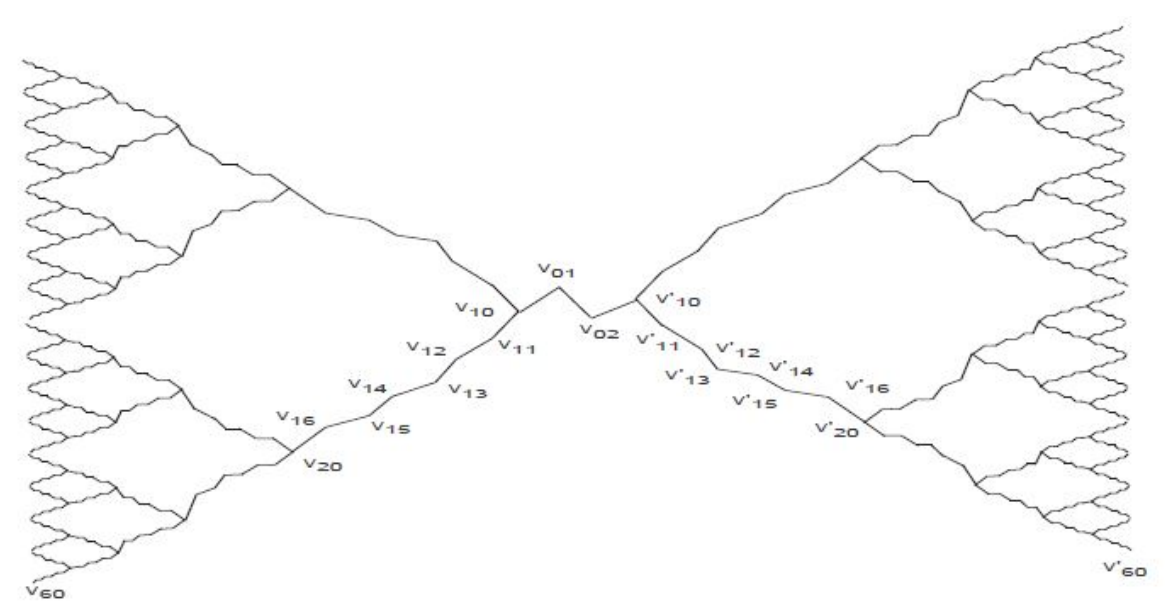

Figure 2.2: The two dimensional structure of regular dendrimer $H[n]$ for $n=5$.

Corollary 2.2. Using equation 2.1, the following results follows:
(i) $M_{1}(G[n])=Z_{1,0}(G[n])=4.2^{n+3}+18.2^{n+1}-50$
(ii) $M_{2}(G[n])=\frac{1}{2} Z_{1,1}(G[n])=4.2^{n+3}+20.2^{n+1}-56$,
(iii) $F(G[n])=Z_{2,0}(G[n])=8.2^{n+3}+44.2^{n+1}-118$,
(iv) $\operatorname{ReZM}(G[n])=Z_{2,1}(G[n])=16.2^{n+3}+96.2^{n+1}-260$,
(v) $M^{a}(G[n])=Z_{a-1,0}(G[n])=\left(2^{n+3}-5\right) \cdot 2^{a}+\left(3 \times 2^{n+1}-6\right)\left(2^{a-1}+3^{a-1}\right)+2^{n+1}\left(2^{a-1}+1\right)$,
(vi) $R_{a}(G[n])=\frac{1}{2} Z_{a, a}(G[n])=\left(2^{n+5}-5\right) \cdot 2^{2 a}+\left(3 \times 2^{n+1}-6\right) \cdot 2^{a} \cdot 3^{a}+2^{n+1} \cdot 2^{a}$,
(vii) $\operatorname{SDD}(G[n])=Z_{1,-1}(G[n])=2.2^{n+3}+18.2^{n}-23$.

Now, we consider the regular dendrimer $H[n]$ where, $n$ is the steps of growth. The edge sets of $H[n]$ can be partitioned as follows:

$$
\begin{aligned}
& E_{1}(H[n])=\left\{e=u v \in E(H[n]): d_{H[n]}(u)=2 \text { and } d_{H[n]}(v)=2\right\} \\
& E_{2}(H[n])=\left\{e=u v \in E(H[n]): d_{H[n]}(u)=2 \text { and } d_{H[n]}(v)=3\right\} \\
& E_{3}(H[n])=\left\{e=u v \in E(H[n]): d_{H[n]}(u)=2 \text { and } d_{H[n]}(v)=1\right\}
\end{aligned}
$$

note that, $\left|E_{1}(H[n])\right|=\left(5 \times 2^{n+2}-19\right),\left|E_{2}(H[n])\right|=\left(3 \times 2^{n+1}-6\right),\left|E_{3}(H[n])\right|=2^{n+1}$. The two dimensional structure of $H[n]$ with 5 -levels is shown in figure 2 .

Theorem 2.3. The $(a, b)$-Zagreb index of the regular dendrimer $H[n]$ is given by

$$
Z_{a, b}(H[n])=\left(5 \times 2^{n+2}-19\right) \cdot 2^{a+b+1}+\left(3 \times 2^{n+1}-6\right)\left(2^{a} \cdot 3^{b}+2^{b} \cdot 3^{a}\right)+2^{n+1}\left(2^{a}+2^{b}\right)
$$


Proof. Applying the definition of (a,b)-Zagreb index, we get

$$
\begin{aligned}
Z_{a, b}(H[n]) & =\sum_{u v \in E(H[n])}\left(d_{H[n]}(u)^{a} d_{H[n]}(v)^{b}+d_{H[n]}(u)^{b} d_{H[n]}(v)^{a}\right) \\
& =\sum_{u v \in E_{1}(H[n])}\left(2^{a} 2^{b}+2^{b} 2^{a}\right)+\sum_{u v \in E_{2}(H[n])}\left(2^{a} 3^{b}+2^{b} 3^{a}\right)+\sum_{u v \in E_{3}(H[n])}\left(2^{a} 1^{b}+2^{b} 1^{a}\right) \\
& =\left|E_{1}(H[n])\right|\left(2^{a} 2^{b}+2^{b} 2^{a}\right)+\left|E_{2}(H[n])\right|\left(2^{a} 3^{b}+2^{b} 3^{a}\right)+\left|E_{3}(H[n])\right|\left(2^{a} 1^{b}+2^{b} 1^{a}\right) \\
& =\left(5 \times 2^{n+2}-19\right) \cdot 2^{a+b+1}+\left(3 \times 2^{n+1}-6\right)\left(2^{a} 3^{b}+2^{b} 3^{a}\right)+2^{n+1}\left(2^{a}+2^{b}\right) .
\end{aligned}
$$

Hence, the theorem.

Corollary 2.4. From equation 2.2, the following results follows:

$$
\begin{array}{ll}
\text { (i) } M_{1}(H[n]) & =Z_{1,0}(H[n])=20.2^{n+2}+18 \cdot 2^{n+1}-106, \\
\text { (ii) } M_{2}(H[n]) & =\frac{1}{2} Z_{1,1}(H[n])=20.2^{n+2}+20.2^{n+1}-112, \\
\text { (iii) } F(H[n]) & =Z_{2,0}(H[n])=40.2^{n+2}+44 \cdot 2^{n+1}-230 \\
\text { (iv) } \operatorname{ReZM}(H[n]) & =Z_{2,1}(H[n])=80.2^{n+2}+96.2^{n+1}-484, \\
\text { (v) } M^{a}(H[n]) & =Z_{a-1,0}(H[n])=\left(5 \times 2^{n+2}-19\right) \cdot 2^{a}+\left(3 \times 2^{n+1}-6\right)\left(2^{a-1}+3^{a-1}\right)+2^{n+1}\left(2^{a-1}+1\right), \\
\text { (vi) } R_{a}(H[n]) & =\frac{1}{2} Z_{a, a}(H[n])=\left(5 \times 2^{n+2}-19\right) \cdot 2^{2 a}+\left(3 \times 2^{n+1}-6\right) \cdot 2^{a} .3^{a}+2^{n+1} \cdot 2^{a}, \\
\text { (vii) } S D D(H[n]) & =Z_{1,-1}(H[n])=10.2^{n+2}+18 \cdot 2^{n}-51 .
\end{array}
$$

Now, we obtained the (a,b)-Zagreb index for the porphyrin dendrimer $D_{n} P_{n}$ with $n$-layers. Here $n=2^{m}(m \geq 2)$ denote the steps of growth. Note that total number of vertices in $D_{n} P_{n}$ is $(96 n-10)$ and $(105 n-11)$ edges. The edge sets of $D_{n} P_{n}$ are divided as follows:

$$
\begin{aligned}
& E_{1}\left(D_{n} P_{n}\right)=\left\{e=u v \in E\left(D_{n} P_{n}\right): d_{D_{n} P_{n}}(u)=1 \text { and } d_{D_{n} P_{n}}(v)=3\right\} \\
& E_{2}\left(D_{n} P_{n}\right)=\left\{e=u v \in E\left(D_{n} P_{n}\right): d_{D_{n} P_{n}}(u)=1 \text { and } d_{D_{n} P_{n}}(v)=4\right\} \\
& E_{3}\left(D_{n} P_{n}\right)=\left\{e=u v \in E\left(D_{n} P_{n}\right): d_{D_{n} P_{n}}(u)=2 \text { and } d_{D_{n} P_{n}}(v)=2\right\} \\
& E_{4}\left(D_{n} P_{n}\right)=\left\{e=u v \in E\left(D_{n} P_{n}\right): d_{D_{n} P_{n}}(u)=2 \text { and } d_{D_{n} P_{n}}(v)=3\right\} \\
& E_{5}\left(D_{n} P_{n}\right)=\left\{e=u v \in E\left(D_{n} P_{n}\right): d_{D_{n} P_{n}}(u)=3 \text { and } d_{D_{n} P_{n}}(v)=3\right\} \\
& E_{6}\left(D_{n} P_{n}\right)=\left\{e=u v \in E\left(D_{n} P_{n}\right): d_{D_{n} P_{n}}(u)=3 \text { and } d_{D_{n} P_{n}}(v)=4\right\}
\end{aligned}
$$

where, $\left|E_{1}\left(D_{n} P_{n}\right)\right|=2 n,\left|E_{2}\left(D_{n} P_{n}\right)\right|=24 n,\left|E_{3}\left(D_{n} P_{n}\right)\right|=10 n-5,\left|E_{4}\left(D_{n} P_{n}\right)\right|=48 n-6,\left|E_{5}\left(D_{n} P_{n}\right)\right|=13 n,\left|E_{6}\left(D_{n} P_{n}\right)\right|=8 n$. The figure of porphyrin dendrimer $D_{n} P_{n}$ with 16-layers is shown in figure 3 .

Theorem 2.5. The $(a, b)$-Zagreb index of regular dendrimer $D_{n} P_{n}$ is given by

$$
Z_{a, b}\left(D_{n} P_{n}\right)=2 n\left(3^{a}+3^{b}\right)+24 n\left(4^{a}+4^{b}\right)+(10 n-5) \cdot 2^{a+b+1}+(48 n-6)\left(2^{a} 3^{b}+2^{b} 3^{a}\right)+26 n \cdot 3^{a+b}+8 n\left(3^{a} 4^{b}+3^{b} 4^{a}\right) .
$$

Proof. From definition of (a,b)-Zagreb index, we get

$$
\begin{aligned}
Z_{a, b}\left(D_{n} P_{n}\right)= & \sum_{u v \in E\left(D_{n} P_{n}\right)}\left(d_{D_{n} P_{n}}(u)^{a} d_{D_{n} P_{n}}(v)^{b}+d_{D_{n} P_{n}}(u)^{b} d_{D_{n} P_{n}}(v)^{a}\right) \\
= & \sum_{u v \in E_{1}\left(D_{n} P_{n}\right)}\left(1^{a} 3^{b}+1^{b} 3^{a}\right)+\sum_{u v \in E_{2}\left(D_{n} P_{n}\right)}\left(1^{a} 4^{b}+1^{b} 4^{a}\right)+\sum_{u v \in E_{3}\left(D_{n} P_{n}\right)}\left(2^{a} 2^{b}+2^{b} 2^{a}\right)+\sum_{u v \in E_{4}\left(D_{n} P_{n}\right)}\left(2^{a} 3^{b}+2^{b} 3^{a}\right) \\
& +\sum_{u v \in E_{5}\left(D_{n} P_{n}\right)}\left(3^{a} 3^{b}+3^{b} 3^{a}\right)+\sum_{u v \in E_{6}\left(D_{n} P_{n}\right)}\left(3^{a} 4^{b}+3^{b} 4^{a}\right) \\
= & \left|E_{1}\left(D_{n} P_{n}\right)\right|\left(1^{a} 3^{b}+1^{b} 3^{a}\right)+\left|E_{2}\left(D_{n} P_{n}\right)\right|\left(1^{a} 4^{b}+1^{b} 4^{a}\right)+\left|E_{3}\left(D_{n} P_{n}\right)\right|\left(2^{a} 2^{b}+2^{b} 2^{a}\right)+\left|E_{4}\left(D_{n} P_{n}\right)\right|\left(2^{a} 3^{b}+2^{b} 3^{a}\right) \\
& +\left|E_{5}\left(D_{n} P_{n}\right)\right|\left(3^{a} 3^{b}+3^{b} 3^{a}\right)+\left|E_{6}\left(D_{n} P_{n}\right)\right|\left(3^{a} 4^{b}+3^{b} 4^{a}\right) \\
= & 2 n\left(3^{a}+3^{b}\right)+24 n\left(4^{a}+4^{b}\right)+(10 n-5) \cdot 2^{a+b+1}+(48 n-6)\left(2^{a} 3^{b}+2^{b} 3^{a}\right)+26 n \cdot 3^{a+b}+8 n\left(3^{a} 4^{b}+3^{b} 4^{a}\right) .
\end{aligned}
$$

Hence, the theorem.

Corollary 2.6. Using equation 2.3 , we obtain following results as follows:

$$
\begin{array}{ll}
\text { (i) } M_{1}\left(D_{n} P_{n}\right) & =Z_{1,0}\left(D_{n} P_{n}\right)=542 n-50, \\
\text { (ii) } M_{2}\left(D_{n} P_{n}\right) & =\frac{1}{2} Z_{1,1}\left(D_{n} P_{n}\right)=643 n-56, \\
\text { (iii) } F\left(D_{n} P_{n}\right) & =Z_{2,0}\left(D_{n} P_{n}\right)=1666 n-118, \\
\text { (iv) } \operatorname{ReZM}\left(D_{n} P_{n}\right) & =Z_{2,1}\left(D_{n} P_{n}\right)=3010 n-260, \\
\text { (v) } M^{a}\left(D_{n} P_{n}\right) & =Z_{a-1,0}\left(D_{n} P_{n}\right)=2 n\left(3^{a-1}+1\right)+24 n\left(4^{a-1}+1\right)+(10 n-5) \cdot 2^{a}+(48 n-6)\left(2^{a-1}+3^{a-1}\right)+26 n \cdot 3^{a-1}+8 n\left(3^{a-1}+4^{a-1}\right), \\
\text { (vi) } R_{a}\left(D_{n} P_{n}\right) & =\frac{1}{2} Z_{a, a}\left(D_{n} P_{n}\right)=2 n \cdot 3^{a}+24 n \cdot 4^{a}+(10 n-5) \cdot 2^{2 a}+(48 n-6) \cdot 2^{a} \cdot 3^{a}+13 n \cdot 3^{2 a}, \\
\text { (vii) } \operatorname{SDD}\left(D_{n} P_{n}\right) & =Z_{1,-1}\left(D_{n} P_{n}\right)=\frac{826}{3} \cdot n-23 .
\end{array}
$$




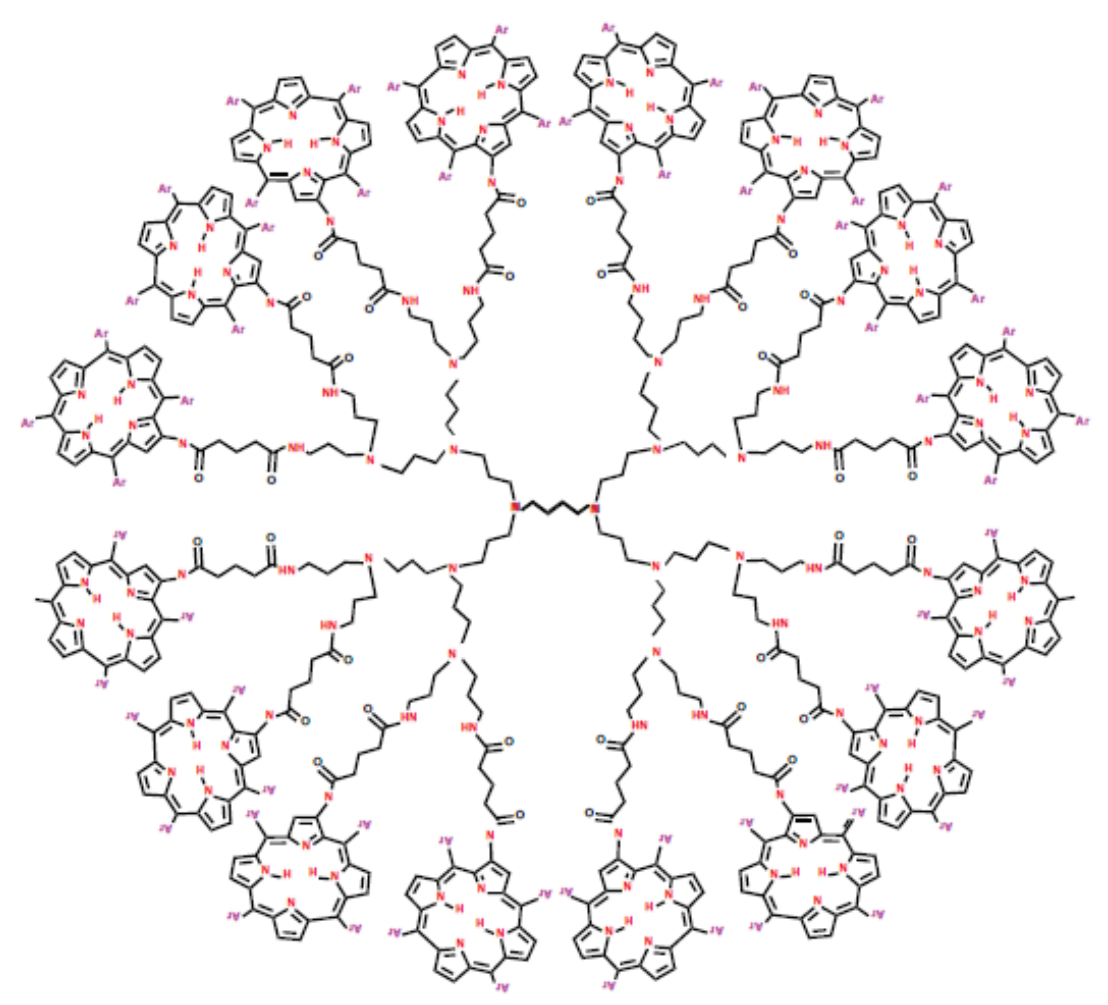

Figure 2.3: Molecular structure of porphyrin dendrimer $D_{16} P_{16}$.

finally, we obtained (a,b)-Zagreb index of Zinc-porphyrin $D P Z_{n}$ here $n$ is defined the steps of growth $(n \geq 1)$. The Zinc-porphyrin $D P Z_{n}$ consists four similar branches and contains a central core. The total number of vertices in $D P Z_{n}$ are $\left(56 \times 2^{n}-7\right)$ and $\left(64 \times 2^{n}-4\right)$ number of edges. The edge set of $D P Z_{n}$ is partitioned as follows:

$$
\begin{aligned}
& E_{1}\left(D P Z_{n}\right)=\left\{e=u v \in E\left(D P Z_{n}\right): d_{D P Z_{n}}(u)=2 \text { and } d_{D P Z_{n}}(v)=2\right\} \\
& E_{2}\left(D P Z_{n}\right)=\left\{e=u v \in E\left(D P Z_{n}\right): d_{D P Z_{n}}(u)=2 \text { and } d_{D P Z_{n}}(v)=3\right\} \\
& E_{3}\left(D P Z_{n}\right)=\left\{e=u v \in E\left(D P Z_{n}\right): d_{D P Z_{n}}(u)=3 \text { and } d_{D P Z_{n}}(v)=3\right\} \\
& E_{4}\left(D P Z_{n}\right)=\left\{e=u v \in E\left(D P Z_{n}\right): d_{D P Z_{n}}(u)=3 \text { and } d_{D P Z_{n}}(v)=4\right\}
\end{aligned}
$$

note that, $\left|E_{1}\left(D P Z_{n}\right)\right|=16 \times 2^{n}-4,\left|E_{2}\left(D P Z_{n}\right)\right|=40 \times 2^{n}-16,\left|E_{3}\left(D P Z_{n}\right)\right|=8 \times 2^{n}+12,\left|E_{4}\left(D P Z_{n}\right)\right|=4$. The figure of Zinc-porphyrin $D P Z_{n}$ with 4 layers is shown in figure 4.

Theorem 2.7. For $\left(D P Z_{n}\right)$, the $(a, b)$-Zagreb index is

$$
Z_{a, b}\left(D P Z_{n}\right)=\left(16 \times 2^{n}-4\right) \cdot 2^{a+b+1}+\left(40 \times 2^{n}-16\right)\left(2^{a} \cdot 3^{b}+2^{b} \cdot 3^{a}\right)+\left(8 \times 2^{n}+12\right) 2 \cdot 3^{a+b}+4\left(3^{a} 4^{b}+3^{b} 4^{a}\right) .
$$

Proof. Using the concept of (a,b)-Zagreb index, we get

$$
\begin{aligned}
Z_{a, b}\left(D P Z_{n}\right) & =\sum_{u v \in E\left(D P Z_{n}\right)}\left(d_{D P Z_{n}}(u)^{a} d_{D P Z_{n}}(v)^{b}+d_{D P Z_{n}}(u)^{b} d_{D P Z_{n}}(v)^{a}\right) \\
& =\sum_{u v \in E_{1}\left(D P Z_{n}\right)}\left(2^{a} 2^{b}+2^{b} 2^{a}\right)+\sum_{u v \in E_{2}\left(D P Z_{n}\right)}\left(2^{a} 3^{b}+2^{b} 3^{a}\right)+\sum_{u v \in E_{3}\left(D P Z_{n}\right)}\left(3^{a} 3^{b}+3^{b} 3^{a}\right)+\sum_{u v \in E_{4}\left(D P Z_{n}\right)}\left(3^{a} 4^{b}+3^{b} 4^{a}\right) \\
& =\left|E_{1}\left(D P Z_{n}\right)\right|\left(2^{a} 2^{b}+2^{b} 2^{a}\right)+\left|E_{2}\left(D P Z_{n}\right)\right|\left(2^{a} 3^{b}+2^{b} 3^{a}\right)+\left|E_{3}\left(D P Z_{n}\right)\right|\left(3^{a} 3^{b}+3^{a} 3^{b}\right)+\left|E_{4}\left(D P Z_{n}\right)\right|\left(3^{a} 4^{b}+4^{a} 3^{b}\right) \\
& =\left(16 \times 2^{n}-4\right) \cdot 2^{a+b+1}+\left(40 \times 2^{n}-16\right)\left(2^{a} \cdot 3^{b}+2^{b} \cdot 3^{a}\right)+\left(8 \times 2^{n}+12\right) 2 \cdot 3^{a+b}+4\left(3^{a} 4^{b}+3^{b} 4^{a}\right) .
\end{aligned}
$$

Which is the desired result.

Corollary 2.8. From equation 2.4, we derived the following results,

$$
\begin{array}{ll}
\text { (i) } M_{1}\left(D P Z_{n}\right) & =Z_{1,0}\left(D P Z_{n}\right)=312 \cdot 2^{n}+4 \\
\text { (ii) } M_{2}\left(D P Z_{n}\right) & =\frac{1}{2} Z_{1,1}\left(D P Z_{n}\right)=376.2^{n}+60, \\
\text { (iii) } F\left(D P Z_{n}\right) & =Z_{2,0}\left(D P Z_{n}\right)=792 \cdot 2^{n}+76 \\
\text { (iv) } \operatorname{ReZM}\left(D P Z_{n}\right) & =Z_{2,1}\left(D P Z_{n}\right)=1888 \cdot 2^{n}+440, \\
\text { (v) } M^{a}\left(D P Z_{n}\right) & =Z_{a-1,0}\left(D P Z_{n}\right)=\left(16 \times 2^{n}-4\right) \cdot 2^{a}+\left(40 \times 2^{n}-16\right)\left(2^{a-1}+3^{a-1}\right)+\left(8 \times 2^{n}+12\right) \cdot 2 \cdot 3^{a-1}+4\left(3^{a-1}+4^{a-1}\right), \\
\text { (vi) } R_{a}\left(D P Z_{n}\right) & \left.=\frac{1}{2} Z_{a, a}\left(D P Z_{n}\right)=\left(16 \times 2^{n}-4\right) \cdot 2^{2 a}+\left(40 \times 2^{n}-16\right) 2^{a} \cdot 3^{a}+\left(8 \times 2^{n}+12\right) \cdot 3^{2 a}+4 \cdot 3^{a} \cdot 4^{a}\right), \\
\text { (vii) } S D D\left(D P Z_{n}\right) & =Z_{1,-1}\left(D P Z_{n}\right)=\frac{404}{3} \cdot 2^{n}-\frac{31}{3} .
\end{array}
$$




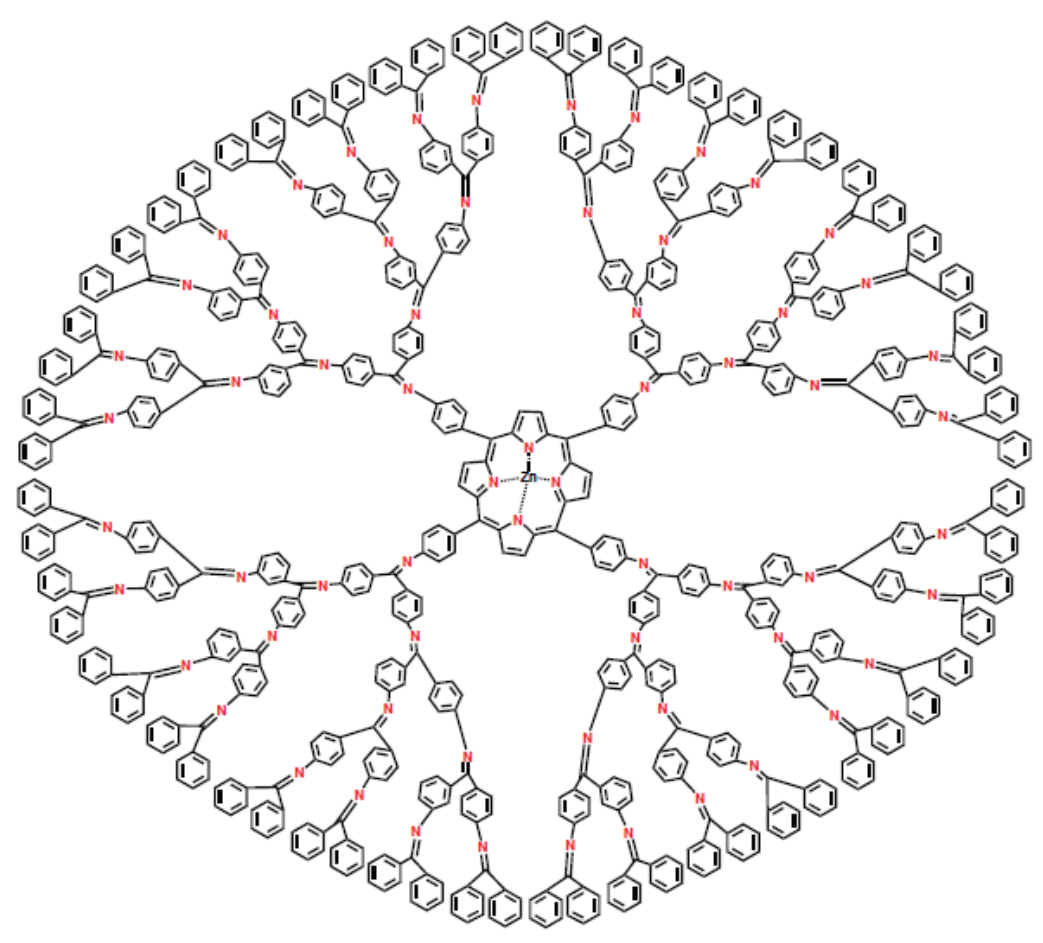

Figure 2.4: Molecular structure of dendrimer zinc porphyrin $D P Z_{4}$.

\section{Conclusions}

In this study, we obtain some closed expressions of the $(a, b)$-Zagreb index of some regular dendrimers such as $G[n], H[n]$, porphyrin dendrimers $D_{n} P_{n}$ and the Zinc-porphyrin $D P Z_{n}$ and hence obtain some other important degree based topological indices for some particular values of $a$ and $b$ from our derived results. For further study the $(a, b)$-Zagreb index of some other chemical structures can be computed.

\section{Acknowledgement}

The first author would like to thank CSIR, HRDG, New Delhi, India for their financial support under the grants no. 09/973(0016)/2017-EMR-I.

\section{References}

[1] D.A. Tomalia, H. Baker, J.R. Dewald, M. Hall, G. Kallos, S. Martin, J. Roeek, J. Ryder, and P. Smith, A new class of polynomials: starburst-dendritic macromolecules, Polym. J., 17, (1985), 117-132.

[2] U. Ahmad, S. Ahmad, and R. Yousaf, Computation of Zagreb and atom-bond connectivity indices of certain families of dendrimers by using automorphism group action, J. Serb. Chem. Soc., 82, (2),(2017), 151-162.

[3] Y. Bashir, A. Aslam, M. Kamran, M.I. Qureshi, A. Jahangir, M. Rafiq, N. Bibi, and N. Muhammad, On forgotten topological indices of some dendrimers structure, Molecules, 22, (867), (2017), 1-8.

[4] I. Gutman, N. Trinajestić, Graph theory and molecular orbitals total $\pi$-electron energy of alternant hydrocarbons, Chem. Phys. Lett., 17, (1972), 535-538.

[5] N. De, The vertex Zagreb indices of some graphs operations, Carpathian Math. Publ., 8, (2), (2016), 215-223.

[6] P. Sarkar, N. De, and A. Pal, The Zagreb indices of graphs based on new operations related to the join of graphs, J. Int. Math. Virtual Inst., 7,(2017), $181-209$.

[7] P. Sarkar, N. De., and A. Pal, F-index of graphs based on new operations related to the join of graphs, arXiv:1709.06301v1.

[8] N. De, On molecular topological properties of TiO2 nanotubes, J. Nanoscience, 2016, (2016), DOI: 1028031.

[9] S. Akhtar, M. Imran, Computing the forgotten topological index of four operations on graphs, AKCE Int. J. Graphs Comb., 14, (1), (2017), 70-79.

[10] P.S. Ranjini, V. Lokesha, and A. Usha, Relation between phenylene and hexagonal squeeze using harmonic index, Int. J. Graph Theory, 1,(2013), $116-121$.

[11] B. Zhao, J. Gan, and H. Wu, Redefined Zagreb indices of some nano structures, Appl. Math. Nonlinear Sci., 1, (1), (2016), 291-300.

[12] R.P. Kumar, D.S. Nandappa, and M.R.R. Kanna, Redefined zagreb, Randić, Harmonic, GA indices of graphene, Int. J. Math. Anal., 11, (10), (2017), $493-502$.

[13] X. Li, J. Zheng, A unified approach to the extremal trees for different indices, MATCH Commun. Math. Comput. Chem., 54, (2005), 195-208.

[14] I. Gutman, M. Lepović, Choosing the exponent in the definition of the connectivity index, J. Serb. Chem. Soc., 66,(9),(2001), 605-611.

[15] V. Lokesha, T. Deepika, Symmetric division deg index of tricyclic and tetracyclic graphs, Int. J. Sci. Eng. Res, 7, (5), (2016), 53-55.

[16] V. Alexander, Upper and lower bounds of symmetric division deg index, Iran. J. Math. Chem., 52, (2014), 91-98.

[17] C.K. Gupta, V. Lokesha, B.S. Shwetha, and P.S. Ranjini, Graph operations on the symmetric division deg index of graphs, Palestine. J. Math., 6, (1), (2017), 280-286.

[18] M. Azari, A. Iranmanesh, Generalized Zagreb index of graphs, Studia Univ. Babes-Bolyai., 56,(3), (2011), 59-70.

[19] M. R. Farahani, The generalized Zagreb index of circumcoronene series of benzenoid, J. Appl. Phys. Sci. Int., 3,(3), (2015), 99-105.

[20] P. Sarkar, N. De, and A. Pal, The $(a, b)$-Zagreb index of nanostar dendrimers, preprint.

[21] M. R. Farahani, M. R. R. Kanna, Generalized Zagreb index of V-phenylenic nanotubes and nanotori, J. Chem. Pharm. Res., 7,(11), (2015), 241-245. 